\title{
O uso dos motores de busca na Internet: como se configuram as pesquisas de conteúdo na Web para a produção de trabalhos educacionais
}

\author{
Alan Correa, Mariusa Warpechowski, Andrio S. Pinto \\ Faculdade Cenecista de Osório (FACOS), Osório, RS - Brasil \\ \{alan.correa.sul@gmail.com, mariusaw@gmail.com, andriosp@gmail.com\}
}

\begin{abstract}
This paper aims to demonstrate how to setup a content search on the Internet by the students of the class of Information Technology Bachelor's of FACOS, the composition of textual works with the use of search engines. This class was accompanied in two classes, with the browsing history of the Internet browser and analyzed questionnaires, with a view to collecting data for analysis. This study demonstrated Google as preferred choice for conducting research content, and the impacts that filters search this site produce the research process on the Web.
\end{abstract}

Resumo. Este artigo tem por objetivo demonstrar como se configura a pesquisa de conteúdo na Internet, por parte dos alunos da turma de Tecnologia da Informação do curso de Letras da FACOS, na composição de trabalhos textuais com o uso dos motores de busca. Essa turma foi acompanhada em duas aulas, tendo o histórico de navegação do browser de Internet analisado e questionários aplicados, com vistas ao levantamento de dados para as análises. Este estudo demonstrou o Google como escolha preferida para a realização de pesquisas de conteúdo, e os impactos que os filtros de busca deste site produzem nos processo de pesquisa na Web.

\section{Introdução}

É importante que as Tecnologias Educacionais ultrapassem o simples ato de adquirir instrumentos de comunicação e utilizá-los no ambiente da escola, ou seja, é necessário trazer para o contexto da escola as informações presentes nas tecnologias e as próprias ferramentas tecnológicas, articulando-as com os conhecimentos escolares e propiciando a interlocução entre os indivíduos [Marques, 2012].

Essa articulação entre as ferramentas tecnológicas e os conhecimentos escolares pode ser colocada em prática através de pesquisas escolares. As pesquisas escolares foram profundamente influenciadas pela adesão ao despertar da Internet, com políticas públicas federais que incentivaram a formação de Laboratórios de Informática nas escolas públicas, disparando o acesso à Informação. Essa nova forma de adquirir informação, mudou evidentemente o método para criação de trabalhos escolares, onde as pesquisas outrora realizadas em outras fontes de pesquisas, como enciclopédias, livros e compêndios agora passam a ser realizadas na Internet.

Os Motores de busca trouxeram maior agilidade para as pesquisas na Web, e com seus algoritmos sofisticados possibilitam que seu sistema de Web Crawlers 
[Coelho e Azevedo, 2008] vasculhe a Internet em busca de resultados relevantes e possíveis informações úteis a serem armazenadas na sua base de dados. Apesar de a informação estar disponível, a tarefa de encontrar o que se necessita não é fácil. A facilidade de pesquisar e a quantidade de informações se configuram em um problema, ao passo que, a quantidade de links, páginas, sites e arquivos se tornaram excessivos, provocando morosidade, impaciência e falta de objetividade para escolher entre milhares de páginas e links devolvidos pelas pesquisas realizadas na Internet.

Cabe ao aluno saber realizar a pesquisa de uma maneira eficiente para que a busca por informações se torne mais fácil. E é a partir da realização de uma pesquisa eficiente que é colocada em prática a abordagem construcionista, que segundo [Albuquerque, 2011], essa abordagem provoca situações em que o ensino seja minimamente valorizado, possibilitando ao aluno à descoberta e a construção do conhecimento.

A proposta deste trabalho é observar como se realizam as pesquisas de conteúdo com a utilização dos Motores de Buscas por parte dos estudantes da educação regular, com vistas na composição de seus trabalhos escolares, se apropriando da Informática Informação Rápida - e todas as possibilidades de conhecimento e investigação que a rede mundial de computadores proporciona. A observação se estende à utilidade dos filtros de busca, procura-se saber se eles são utilizados e qual a importância do uso destes filtros.

Este artigo está organizado da seguinte forma, a seção 2 descreve o que são os Motores de busca e seu funcionamento, bem como os filtros de busca. Na seção 3 é apresentada a metodologia da pesquisa, na seção 4 são apresentados os resultados e finalmente a seção 5 descreve as considerações finais.

\section{Motores de busca}

Os motores de busca, do inglês Search Engine, tiveram sua primeira implementação a partir de Alan Emtage no ano de 1990 e tinham a função de indexar arquivos do computador. Essa foi a ideia principal que desencadeou as novas técnicas de busca que surgiram posteriormente, como a indexação de conteúdo Web pelos motores de busca na Internet.

Os motores de busca, ou sistemas de busca [Campos, 2005], são recursos de extrema importância para a busca de informação, em diversos formatos, na rede mundial de computadores. Sobre os motores de busca, o autor diz:

Um sistema de busca é um conjunto organizado de computadores, índices, bases de dados e algoritmos, reunidos com a missão de analisar e indexar as páginas web, armazenar os resultados dessa análise e indexação numa base de dados e devolvê-los posteriormente quando de uma pesquisa que preencha os requisitos indicados pelo utilizador por ocasião de uma consulta. As suas funções são, portanto as de crawling, index e searching [Campos, 2005, p. 8].

De acordo com Google [Google, 2011], Motor de Busca é uma "função computadorizada que rastreia a informação disponível na Internet, utilizando palavraschave ou outros termos específicos. Esta informação tem que ser previamente rastreada (crawled) e indexada.".

Nesse sentido, podemos observar na Figura 1 a arquitetura e o funcionamento dos motores de busca.

O crawling (robot ou spider) é um software e tem a função de rastrear cada link 
de páginas na Internet, ordenando e criando uma lista de páginas. Em [Google, 2011], encontra-se que o "rastreio ( $\mathrm{crawl}$ ) é uma ação do rastreador (crawler) na busca de conteúdos pela Internet com intuito de indexação". Nessa lógica, Campos [CAMPOS, 2005] diz que "tudo o que o crawling encontrar vai para a segunda parte do motor de busca, o index", como ilustrado na figura supracitada.

$\mathrm{O}$ index (indexação) tem a função de classificar e organizar a informação. Ele é como um livro que contém uma cópia de todas as páginas web que o spider encontra. As mesmas podem ser usadas para construir um índice invertido de palavras-chave para posterior classificação dos documentos em diretórios, ou para a construção de um grafo de hyperlinks para desenvolver um ranking de links [Campos, 2005].

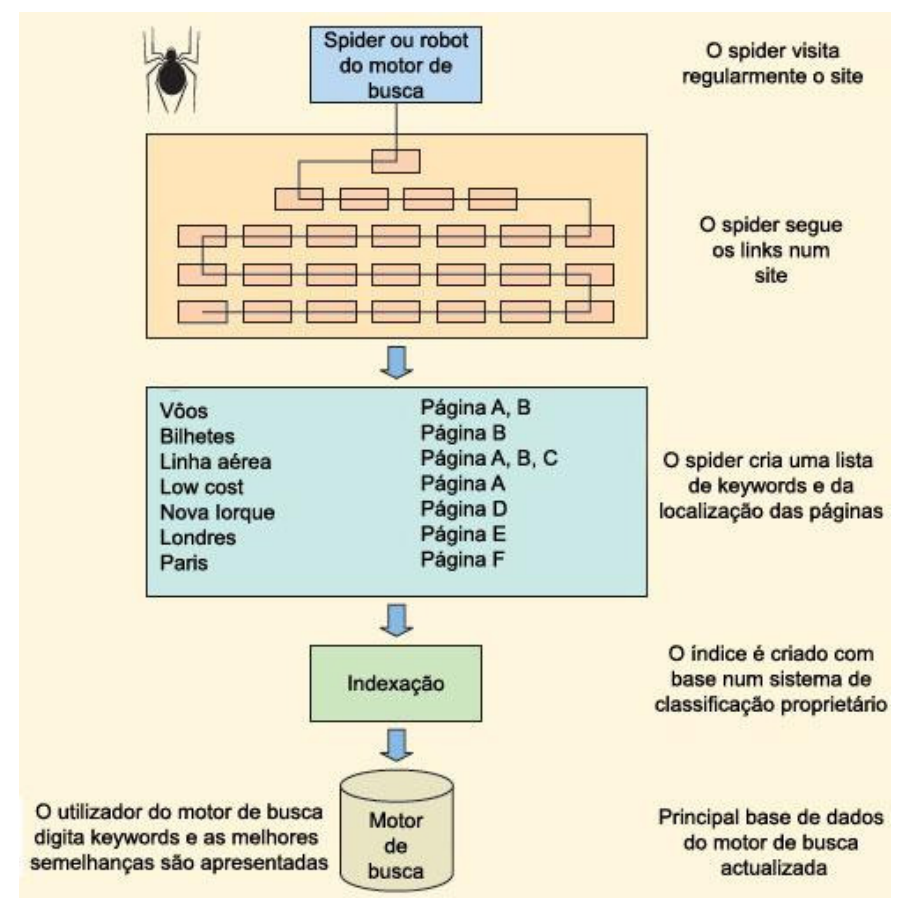

Figura 1: Arquitetura e funcionamento dos motores de busca. Fonte: http://evoluindonainformatica.wordpress.com/author/lanalbs/

O searching (busca) é disparado quando o usuário solicita informações para que o Search Engine devolva uma série de informações baseadas nos termos digitados na caixa de pesquisa. Os motores de busca utilizam essas técnicas para percorrer a Internet, aplicando um conjunto de técnicas e ordenando as páginas por sua importância, exibindo o resultado desse processo ao usuário.

Tipicamente os motores de busca utilizam robots para vasculhar a web, guardam cópias das páginas e procedem à sua indexação, aplicando um conjunto de algoritmos que definem a relevância de uma página. Os parâmetros de relevância definidos para o retorno de páginas, no contexto da pesquisa em bibliotecas digitais, devem seguir, no entanto, outros critérios que os definidos pelos motores de busca. [Campos, 2005]

É importante realçar que devido a diferenças na implementação dos algoritmos dos diversos motores de busca, os resultados constantemente irão variar. Considerando 
a presença extensiva dos motores de busca, seus diferentes algoritmos e diversificadas opções em motores de busca, como os dos sites Yahoo! ${ }^{1}$, Google $^{2}$, Bing $^{3}$, Ask $^{4}$.

\subsection{Filtros de busca}

No contexto atual, o fluxo ágil do compartilhamento em massa da informação digital criada e recriada na Web, devido ao crescimento exponencial ao acesso a Internet, dispara uma reflexão importante que pode ser percebida na fala de Eco [Eco, 2000], pois ele alerta para um problema importante ao destacar que a Internet "é como uma enchente e não há como parar a invasão de informação". O autor ainda alerta que o excesso de informação tende a tornar-se prejudicial, devido à dificuldade em selecionar a informação de forma adequada. Esse autor enfatiza que é imprescindível discernir a informação de qualidade no "dilúvio de informação" em que estamos "mergulhados". Embora a rede mundial de computadores tenha a capacidade de conceber e prover o acesso rápido à informação, a escola e os professores têm a responsabilidade de conduzir, de forma pedagógica e crítica, os alunos a obterem o direito ao acesso e a leitura dessas informações. Nessa direção, Borba e Penteado [Borba, 2001] enfatizam que:

O acesso à Informática deve ser visto como um direito e, portanto, nas escolas públicas e particulares o estudante deve poder usufruir de uma educação que no momento atual inclua, no mínimo, uma "alfabetização tecnológica". Tal alfabetização deve ser vista não como um curso de Informática, mas, sim, como um aprender a ler essa nova mídia.

Visando a "alfabetização tecnológica" dos motores de busca é de extrema importância o aprendizado de técnicas para melhorar as pesquisa realizadas na Internet. Nesse sentido, os filtros de busca podem contribuir significativa e positivamente para uma pesquisa mais ágil e objetiva. Para isso, é fundamental o entendimento adequado dos Operadores, Símbolos, Palavras especiais e técnicas avançadas de pesquisa, nos sites de buscas.

\subsubsection{Operadores de pesquisa}

De acordo com [Google, 2013], é possível utilizar operadores de pesquisa ${ }^{5}$ para ter mais controle sobre os resultados visualizados. Esses operadores podem ser adicionados aos termos de pesquisa na caixa de pesquisa do Google. Na Tabela 1 são apresentados os operadores de pesquisa abordados em sala de aula com os alunos participantes da pesquisa.

Tabela 1: Operadores de pesquisa

\begin{tabular}{|l|l|}
\hline Operadores & Utilidade \\
\hline $\begin{array}{l}\text { Pesquisar uma palavra ou frase exata } \\
\text { "consulta de pesquisa" }\end{array}$ & $\begin{array}{l}\text { A pesquisa entre aspas é útil para pesquisar um termo exato. } \\
\text { Ex.:["imagine all the people"]. }\end{array}$ \\
\hline
\end{tabular}

\footnotetext{
${ }^{1}$ Yahoo!: http://br.yahoo.com/

${ }^{2}$ Google: https://www.google.com.br/

${ }^{3}$ Bing: http://br.bing.com/

${ }^{4}$ Ask: http://br.ask.com/

${ }^{5}$ Operadores de Pesquisa do Google. Disponível em: http://goo.gl/isiLu
} 
Excluir uma palavra -consulta
Adicione um hífen (-) antes do termo ou do site para excluir todos os resultados que incluem esse termo. Ex.: [velocidade jaguar -carro], [pandas -site:wikipedia.org ].

\subsubsection{Pontuação e símbolos}

O Google também disponibiliza o recurso de pontuação e símbolos ${ }^{6}$ na pesquisa. Esse recurso utiliza caracteres especiais que modificam os termos de pesquisa para encontrar exatamente o que se procura. Para exemplificar essa lógica é possível utilizar o sinal de porcentagem $(\%)$ para procurar por valores percentuais, como [40\% de 80$]$ ou [10\% de 0,1]. O sinal de cifrão (\$) possibilita indicar preços, de modo que [nikon 400] e [nikon \$400] gerem resultados diferentes. Por sua vez, o sinal de adição (+) possibilita uma busca forçada incluindo um termo na pesquisa. Exemplo: java +apostilas.

\subsubsection{Palavras especiais}

É possível usar o sinal de dois pontos “ : ”, seguido da palavra especial, conforme o Guia de Referência para operações Avançadas com o Google ${ }^{7}$ [Google, 2013], que fará o Google interpretá-la como um filtro de pesquisa. É importante destacar que as palavras especiais não funcionam adequadamente se houver espaço entre os dois pontos “ : " e a palavra pesquisada posteriormente. Nesse sentido, a Tabela 2, ilustra essa técnica.

Tabela 2: Palavras especiais

\begin{tabular}{|l|l|}
\hline Palavras especiais & Utilidade \\
\hline intitle: & $\begin{array}{l}\text { Restringe os resultados aos documentos que contenham no título o termo. Ex.: } \\
\text { [gripe intitle:ajuda] retornará documentos que mencionam a palavra "ajuda" em } \\
\text { seus títulos, e mencionar as palavras "gripe" em qualquer parte do documento } \\
\text { (título ou não). }\end{array}$ \\
\hline filetype: & $\begin{array}{l}\text { Restringe os resultados às páginas ao tipo de arquivo. Ex.: [avaliação } \\
\text { filetype:pdf], [internet filetype:pdf OR filetype:doc]. }\end{array}$ \\
\hline site: & $\begin{array}{l}\text { O Google irá restringir os resultados de busca para o site ou domínio especificado. } \\
\text { Ex.: [download site:alann.besaba.com] irá mostrar informações de download no } \\
\text { site "Alan Alves Correa". Ao utilizar [site:paz:gov] o motor de busca irá encontrar } \\
\text { páginas sobre "paz" dentro do domínio ".gov". }\end{array}$ \\
\hline inurl: & $\begin{array}{l}\text { Restringe os resultados a documentos que contenham a palavra pesquisada na } \\
\text { URL. Ex.: [inurl:saudável comer] retornará documentos que mencionam a palavra } \\
\text { "saudável" em sua URL, e a palavra "comer" em qualquer lugar do documento. }\end{array}$ \\
\hline related & $\begin{array}{l}\text { Retorna lista de páginas web que são semelhantes à página da web especificada. } \\
\text { Ex.: [related:www.lume.ufrgs.br] irá listar páginas web que são semelhantes para } \\
\text { a página inicial do Lume - Ufrgs. }\end{array}$ \\
\hline
\end{tabular}

\subsubsection{Ferramentas de pesquisa}

\footnotetext{
${ }^{6}$ Pontuação e símbolos na pesquisa do Google. Disponível em: http://goo.gl/ym4TZa

${ }^{7}$ Guia de referência para operações avançadas do Google. Disponível em: http://goo.gl/FHbSLg
} 
O Google possui diversos recursos e ferramentas que favorecem a aplicabilidade à pesquisa avançada. Por meio da interface gráfica é possível restringir a pesquisa, em diversos âmbitos, como imagens, vídeos, livros, tipo de resultado, intervalos de datas, páginas hospedada em um país determinado, idioma da página, entre outros. Esses recursos estão disponíveis na parte superior da página do site de busca, como ilustra a Figura 2.

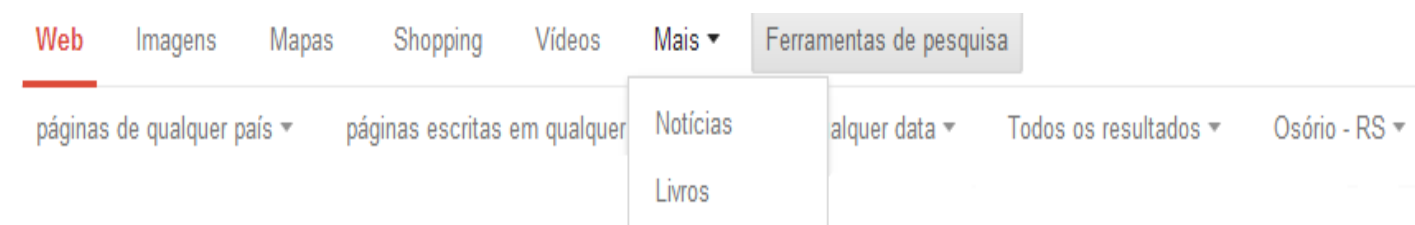

Figura 2: Interface gráfica para pesquisas no Google. Fonte: Autoria Própria, 2013.

É de extrema importância destacar que a aplicação dos recursos não é um fim em si mesmo, e sim, ferramentas que precisam de crítica e lucidez em sua utilização para que o resultado seja adequado. A relação completa de filtros e ferramentas para pesquisa está disponível em: https://www.google.com/insidesearch/tipstricks/index.html. Em face desses recursos, ferramentas e técnicas este trabalho visou compreender o comportamento dos alunos nas pesquisas de conteúdo na Internet, com a utilização dos motores de busca e seus filtros. A investigação buscou demonstrar:

- qual o site de busca mais frequente em pesquisas na Internet;

- qual o conhecimento dos filtros de buscas;

- qual o limite de paginação acessado;

- como se dá a escolha dos links;

- qual o tipo de mídia preferido;

- quais os sites favoritos para a consulta de conteúdo;

- qual a relevância, agilidade e objetividade dos filtros de busca.

\section{Metodologia}

Para obter os resultados foi realizada uma pesquisa estruturada através da aplicação de dois questionários que foram desenvolvidos através do recurso de formulários do Google Docs, bem como a análise do histórico de navegação dos alunos.

A população definida para esta pesquisa foi composta por 37 (trinta e sete) estudantes do primeiro e segundo semestres do curso de Licenciatura em Letras da Faculdade Cenecista de Osório - FACOS, que cursavam a disciplina de Tecnologia da Informação. Num primeiro momento foi solicitado aos alunos que fizessem uma pesquisa na Internet sobre um determinado assunto e que produzissem um mini artigo. Após a realização da pesquisa e da escrita do mini artigo, os alunos responderam a um questionário $^{8}$ formado por 10 (dez) questões. Num segundo momento os alunos receberam uma aula sobre o uso dos filtros de busca do Google e após foram solicitados a fazer uma pesquisa na Internet para produzir um trabalho. Após a realização deste trabalho os alunos responderam a um segundo questionário ${ }^{9}$ formado por 7 (sete) questões.

\footnotetext{
${ }^{8}$ Questionário 1: Disponível em: http://goo.gl/fGN7yw

${ }^{9}$ Questionário 2: Disponível em: http://goo.gl/ak0MP6
} 


\section{Apresentação e Discussão dos Resultados}

Nesta seção são apresentados os resultados obtidos através da aplicação dos questionários e da análise dos históricos de navegação, resultados estes restritos à turma analisada. Inicialmente são descritos os resultados obtidos no primeiro momento da pesquisa, onde os alunos não tinham conhecimento dos filtros de busca, depois são mostrados os resultados do segundo momento, onde antes da pesquisa os alunos receberam uma aula sobre o uso dos filtros de busca do Google e finalmente são expostos os resultados da análise dos históricos de navegação dos alunos.

\subsection{Primeiro momento}

Como resultados da aplicação do primeiro questionário, verificou-se que $100 \%$ dos alunos utilizam o Google para a realização de pesquisas na Internet. Diante dessa realidade, podemos inferir a importância em estudar e ampliar o conhecimento sobre as pesquisas a partir do Google, haja vista, a utilização frequente por parte dos alunos e sua preferência por esse site de pesquisa.

Outra informação relevante foi o desconhecimento dos filtros de busca, por parte dos alunos participantes da pesquisa, onde $76 \%$ dos alunos disseram que não conhecem os filtros de busca. O uso em massa do site de pesquisas Google e o desconhecimento das técnicas de pesquisas avançadas produzem uma ilação importante: necessidade de um olhar voltado a exploração e aquisição de subsídios relevantes que possibilitem alternativas para implementar a forma em como se pesquisa no Google.

A turma pesquisada foi questionada em relação ao limite de paginação de resultados utilizada para consulta. Foi constatado que 35\% (13 alunos) usam geralmente mais do que as 4 primeiras páginas de resultados, 30\% (11 alunos) usam a $1^{\circ}, 2^{\circ}$ e $3^{\circ}$ páginas de resultados, $24 \%$ (9 alunos) usam apenas a $1^{\circ}$ página de resultados, $11 \%$ (4 alunos) usam a $1^{\circ}$ e $2^{\circ}$ página de resultado.

Quando perguntados sobre qual(is) o(s) critério(s) utilizado(s) na escolha do link na página de resultados, os dados levantados se configuraram da seguinte forma: pelo título do link 41\% (15 alunos), pelo resumo 43\% (16 alunos), pelo tipo de formato 3\% ( 1 aluno), acessa os links aleatoriamente 14\% (5 alunos). Nesse sentido, os filtros de busca do Google possibilitam refinar a busca pelo título ou pelo resumo, que são os preferidos pelos alunos pesquisados, utilizando o filtro "intitle" ou usando regras para buscar conteúdos com maior objetividade, como os filtros de busca forçada (+), exclusão de termos (-), pesquisa exata (" "), entre outros.

Os alunos foram solicitados a informar qual(is) o(s) tipo(s) de fonte(s) eles preferem consultar na Internet. As respostas se configuraram da seguinte forma:

- Artigos científicos: 25 alunos (34\%);

- Texto de blogs ou fóruns de discussão: 14 alunos (19\%);

- Capítulos de livros digitais: 11 alunos (15\%);

- Não tenho preferência: 7 alunos (10\%);

- Jornais digitais: 5 alunos (7\%);

- Verbetes de dicionários ou enciclopédias: 3 alunos (4\%);

- Apresentação de slides (Ex.:PPT): 3 alunos (4\%);

- Apostilas Digitais: 3 (4\%);

- Wikis: 1 aluno (1\%);

- Outros: 1 aluno (1\%).

Foi diagnosticado que o tipo de fonte teórica com maior prevalência é a de 
caráter científico. Nesse âmbito, as fontes científicas podem ser buscadas, filtrando-as, por exemplo, restringindo a consulta a sites relacionados ao que se está sendo pesquisado. O filtro de busca related retorna páginas que possuem relação ou semelhança com o site que está sendo apontado na caixa de busca. Por exemplo, realizando a seguinte pesquisa: related:scholar.google.com.br, o Google retornará diversos sites que possuem as mesmas características do Google Acadêmico, mantendo assim, a pesquisa apenas em sites com conteúdo acadêmico. Dessa maneira, os resultados são otimizados e ocorre a redução considerável da quantidade de links e paginação, facilitando a visualização e escolha das fontes de pesquisa nas primeiras páginas de resultados. Sendo assim, o filtro related se mostra útil ao objetivo proposto.

Este trabalho ainda indagou os alunos quanto ao tipo de mídia preferida, com a pergunta: Quais os tipos de mídias você utiliza para consultas na Internet? As respostas dos alunos foram as seguintes:

- Textos online: 28 alunos (37\%);

- Arquivos de textos baixados para o computador: 7 alunos (22\%);

- Imagens: 13 alunos (17\%);

- Vídeos: 12 alunos (16\%);

- Apresentações de Slides (ex.: ppt): 5 alunos (7\%);

- Podcast: 1 aluno (1\%);

- Mapas: 0 aluno (0\%);

- Outros: 0 aluno (0\%).

Diante dessas preferências, o filtro de busca "filetype" auxilia as pesquisas restringindo a busca ao tipo de arquivo, bastando informar a extensão do arquivo após a declaração desse filtro. Por exemplo, para realizar uma pesquisa pertinente ao tema "Java Applet" apenas em arquivos em formato de apresentação de slides, basta declarar na caixa de pesquisa do google o seguinte: java applet filetype:ppt. Dessa forma é possível filtrar conteúdos em qualquer tipo de mídia, de acordo com a especificidade da extensão: pdf, doc, mp3, avi, entre outros.

Observou-se também que o site preferido para consultas é o Google Acadêmico e o Google Livros, confirmando a prevalência em consultas com caráter acadêmico. A totalidade das respostas para essa questão segue abaixo:

- Google acadêmico (http://scholar.google.com.br): 20 alunos (29\%);

- Google livro (http://books.google.com.br): 17 alunos (25\%);

- Wikipédia (http://pt.wikipedia.org): 15 alunos (22\%);

- Domínio público (http://www.dominiopublico.gov.br): 7 alunos (10\%);

- YouTube (http://www.youtube.com): 5 alunos (7\%);

- Lume UFRGS (http://www.lume.ufrgs.br): 2 alunos (3\%);

- Wikilivros (http://pt.wikibooks.org): 1 aluno (1\%);

- Scrib (http://pt.scribd.com): 1 aluno (1\%);

- Periódicos capes (http://www.periodicos.capes.gov.br): 0 aluno (0\%);

- Outros: 0 aluno $(0 \%)$.

Com o auxílio do filtro "site" ou "inurl", é possível buscar termos apenas nos sites e URL's específicas, agilizando dessa forma a busca apenas no(s) site(s) favorito(s).

\subsection{Segundo momento}

$\mathrm{Na}$ segunda etapa da pesquisa os alunos receberam instruções de "como fazer" 
pesquisas na Internet utilizando os filtros e as técnicas avançadas no Google. Depois dessas instruções, aplicação e pesquisa concluída, os alunos responderam ao questionário referente a essa etapa.

Inicialmente, foi levantada a opinião dos alunos sobre a relevância em conhecer as técnicas de pesquisa avançadas. O resultado apresentado demonstrou que todos os 37 alunos $(100 \%)$ atribuíram relevância em conhecer os filtros de busca para a realização de pesquisas na Internet.

Os alunos demonstraram ser importante não apenas conhecer, mas também utilizar os filtros. Nesse sentido, observou-se que a adesão ao uso das técnicas aprendidas foi alta, pois 30 alunos $(81 \%)$ utilizaram pelo menos um filtro durante a pesquisa. Os filtros mais utilizados pelos alunos foram: pesquisa exata (" "), utilizado por 24 alunos (49\%), seguido do filtro filetype utilizado por 11 alunos (22\%) e ainda 7 alunos (14\%) fizeram uso do filtro de busca forçada (+).

Ainda foi questionado sobre o quão ágil as consultas se tornaram com a utilização das técnicas. Entre os 37 alunos questionados, 33 alunos, ou seja, 89\%, responderam que os filtros de busca do Google tornaram as pesquisas mais ágeis.

$\mathrm{Na}$ sequência os alunos avaliaram a utilidade dos filtros de busca que utilizaram na pesquisa. Essa avaliação resultou na aprovação dos filtros utilizados, pois $76 \%$ consideraram útil o uso dos filtros aplicados na pesquisa de conteúdo na Internet.

Esse trabalho ainda visou avaliar o impacto dos filtros como prática recorrente nas próximas pesquisas na Internet, onde $100 \%$ dos alunos respondeu que pretende utilizar os filtros de buscas em futuras pesquisas na Internet.

Através da análise dos históricos de navegação dos alunos foi possível observar que a média de links acessados pelos alunos na primeira pesquisa foi de 54,5 links, e na segunda pesquisa, onde os alunos conheciam e usaram os filtros de busca foi de 14,2. Nesse sentido, constata-se que a média de links visitados sofreu uma importante redução, permitindo afirmar que a utilização dos filtros de busca pode ser um fator importante para a redução do esforço e, consequentemente, do tempo de navegação para a produção do trabalho a ser realizado.

\section{Considerações finais}

O presente artigo procurou verificar como se dá a pesquisa na Internet através dos motores de busca, bem como a importância do uso dos filtros do motor de busca Google. Os filtros de busca se configuraram em recursos importantes para as pesquisas de conteúdo na Internet quando aplicados de forma crítica, em busca do tema desejado. Ao utilizá-los de forma adequada, a pesquisa se torna mais ágil e mais objetiva, demandando menor esforço e tempo na ação de pesquisa, haja vista, os resultados apresentados pelos motores nas primeiras páginas de resultados, tendo títulos, links e resumos com maior pertinência ao tema pesquisado na caixa de busca. Dessa forma, os resultados das primeiras páginas são mais relevantes para o usuário. Não obstante, é válido afirmar que os motores de busca e seus recursos avançados não produzem conteúdos melhores e não tem impacto na qualidade do teor das mídias. Nesse sentido, os filtros de busca contribuem para agilizar as pesquisas e não tornar os conteúdos pesquisados melhores.

O projeto de pesquisa, após sua aplicação provoca algumas conclusões: a busca de informação na imensidão da rede mundial de computadores se configura um desafio importante, considerando o esforço e processo minucioso de busca e refinamento da 
informação recebida através dos motores de busca, embora a pesquisa na Web pareça uma tarefa simples e rápida. $\mathrm{O}$ estudo demonstrou pouco conhecimento por parte dos alunos em relação às técnicas de pesquisas avançadas e tal desconhecimento os levou a um esforço importante ao buscar o conteúdo fragmentado por milhares de páginas sugeridas pelo motor de busca. A partir do estudo dos filtros de busca, os alunos atribuíram relevância no conhecimento e apropriação dos filtros de busca na Internet para suas pesquisas de conteúdo. Não há a pretensão de esgotar o assunto e o tema, mas sim, demonstrar que os motores de buscas e a utilização dos filtros podem ser explorados e estudados de modo a melhorar os processos de ensino-aprendizagem, produção de textos e, com criticidade, propor e fomentar as pesquisas de conteúdo na Internet.

\section{Referências}

Albuquerque, Aparecida Maria Costa de, Fernandes, Alisandra Cavalcante, Filho, José Aires Castro. "Investigando Práticas Educativas Com O Uso De Computadores Na Escola: Uma Abordagem Construcionista Ou Instrucionista?". Anais do XXII SBIE XVII WIE. ISSN: 2176-4301. 2011.

Borba, Marcelo C. e Penteado, Miriam Godoy - "Informática e Educação Matemáticacoleção tendências em Educação Matemática”. Autêntica, Belo Horizonte - 2001.

Campos, Ricardo Nuno Taborda (2005). "Agrupamento Automático de Páginas Web Utilizando Técnicas de Web Content Mining". Disponível em: https://dias.users.greyc.fr/publications/MscRicardo.pdf. Acessado em 17 de jul. 2013.

Coelho, Ricardo.; Azevedo, Rui. "Estudo Comportamental dos Web Crawlers". 2008. Disponível em: http://goo.gl/g8mYH. Acesso: 14 jul. 2013.

Eco, Umberto. "O Dilúvio da informação". (VEJA - Vida Digital). VEJA, ano 33, n. 52, p. 11-15, 04/12/2000.

Google (2011). "Guia do Google de Introdução à Otimização para Motores de Busca (SEO)”. Disponível em: http://goo.gl/SPMOQ. Acessado em 17 de jul. 2013.

Google (2013). “Operadores de pesquisa”. Disponível em: http://goo.gl/isiLu. Acessado: 1 de jul. 2013.

Google (2013). "Pontuação e símbolos". Disponível em: http://goo.gl/LrjFCP. Acesso: 1 de jul. 2013.

Marques, Antonio Carlos, JESUS, Andreia de. "Uma Reflexão sobre o Projeto Um computador por Escola - UCA". Anais do XXIII SBIE - XVIII WIE. ISSN: 23166541. 2012. 